A

\begin{tabular}{|c|c|c|}
\hline-0.82 & -1.08 & $r d g B$ \\
\hline-1.08 & -1.09 & PIP82 \\
\hline-1.44 & -0.97 & $r d g C$ \\
\hline-1.39 & -1.27 & ninaC \\
\hline-1.39 & -1.38 & Cds \\
\hline-0.58 & -0.75 & Pph13 \\
\hline-0.93 & -0.46 & Gprk1 \\
\hline-0.86 & -0.66 & Camta \\
\hline-0.85 & -0.63 & norpA \\
\hline-1.07 & -0.32 & $d c o$ \\
\hline-1.22 & -0.25 & Ekar \\
\hline-1.41 & -0.62 & Ttd14 \\
\hline-1.20 & -0.56 & CarT \\
\hline-1.32 & -0.70 & Galphaq \\
\hline-1.23 & -0.75 & stops \\
\hline-1.79 & -3.39 & Arr2 \\
\hline-1.85 & -3.06 & ninaE \\
\hline-2.89 & -2.32 & trpl \\
\hline-2.33 & -2.53 & tim \\
\hline-1.91 & -1.75 & $\operatorname{trp}$ \\
\hline-1.52 & -2.22 & Arr1 \\
\hline-1.60 & -2.09 & inaD \\
\hline
\end{tabular}

\section{D1 D10}

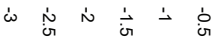

log2RNA-seq fold change relative to $\mathrm{Rh} 1>\mathrm{Ctrl}$

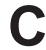

Rh1>

Cyc ${ }^{\mathrm{DN}}$

\section{Rh1>LacZ}

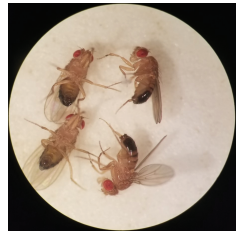

$\mathrm{Rh} 1>\mathrm{Clk}^{\mathrm{DN}}[\mathrm{Chr} 2]$

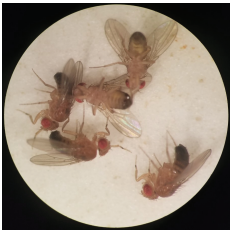

$\mathrm{Rh}_{1}>\mathrm{Cyc}^{\mathrm{DN}}$

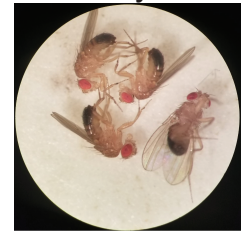

$\mathrm{Rh} 1>\mathrm{Clk}^{\mathrm{DN}}[\mathrm{Chr} 3]$

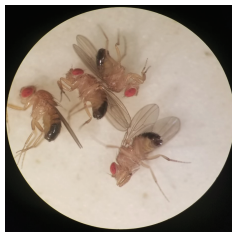

\title{
Genotype
}

$W^{1118} ; P\left\{W^{+m C}=\right.$ UAS-lacZ.Exel $\} 2 /+; P\left\{r y^{+t 7.2}=r h 1-G A L 4\right\} 3, r y^{506 /+}$ $W^{1118} ; P\left\{W^{+m C}=U A S-c y c\right.$. delta $\} 2 /+; P\left\{r y^{+t 7.2}=r h 1-G A L 4\right\} 3, r y^{506 /+}$ $W^{1118} ; P\left\{W^{+m C}=U A S-C / k . D e l t a\right\} 1 /+; P\left\{r y^{+77.2}=r h 1-G A L 4\right\} 3, r y^{506 /+}$ $w^{1118} ;+++; P\left\{w^{+m C}=U A S-C / k \cdot D e l t a\right\} 865 / P\left\{r y^{+7.2}=r h 1-G A L 4\right\} 3, r y^{506}$

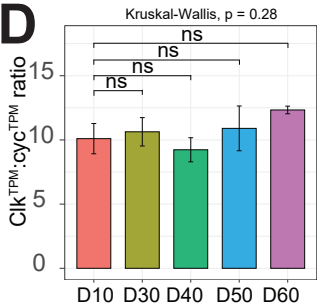

